\title{
Distribution of denitrifying bacterial communities in the stratified water column and sediment-water interface in two freshwater lakes and the Baltic Sea
}

\author{
Ok-Sun Kim • Johannes F. Imhoff • \\ Karl-Paul Witzel · Pilar Junier
}

Received: 31 August 2009/Accepted: 14 July 2010/Published online: 1 August 2010

(C) Springer Science+Business Media B.V. 2010

\begin{abstract}
We have studied the distribution and community composition of denitrifying bacteria in the stratified water column and at the sediment-water interface in lakes Plußsee and Schöhsee, and a nearshore site in the Baltic Sea in Germany. Although environmental changes induced by the stratification
\end{abstract}

Handling Editor: Piet Spaak.

Electronic supplementary material The online version of this article (doi:10.1007/s10452-010-9335-7) contains supplementary material, which is available to authorized users.

\section{O.-S. Kim}

School of Biological Sciences and Institute of Microbiology, Seoul National University, 56-1 Shillimdong, Kwanak-gu, Seoul 151-742, Republic of Korea

O.-S. Kim · K.-P. Witzel

Max-Planck-Institute for Evolutionary Biology, 24306 Plön, Germany

J. F. Imhoff

Leibniz-Institute of Marine Sciences at the University of Kiel, 24148 Kiel, Germany

P. Junier $(\bowtie)$

Laboratory of Microbial Ecology, Institute of Biology, University of Neuchâtel, PO box 158, 2009 Neuchâtel, Switzerland

e-mail: pilar.junier@unine.ch

P. Junier

Ecole Polytechnique Fédérale de Lausanne,

1015 Lausanne, Switzerland of the water column in marine environments are known to affect specific populations of denitrifying bacteria, little information is available for stratified freshwater lakes and brackish water. The aim of the present study was to fill this gap and to demonstrate specific distribution patterns of denitrifying bacteria in specific aquatic habitats using two functional markers for the nitrite reductase (nirK and nirS genes) as a proxy for the communities. The leading question to be answered was whether communities containing the genes nirK and nirS have similar, identical, or different distribution patterns, and occupy the same or different ecological niches. The genes nirK and nirS were analyzed by PCR amplification with specific primers followed by terminal restriction fragment length polymorphism (T-RFLP) and by cloning and sequence analysis. Overall, nirS-denitrifiers were more diverse than nirK-denitrifiers. Denitrifying communities in sediments were clearly different from those in the water column in all aquatic systems, regardless of the gene analyzed. A differential distribution of denitrifying assemblages was observed for each particular site. In the Baltic Sea and Lake Plußsee, nirK-denitrifiers were more diverse throughout the water column, while nirSdenitrifiers were more diverse in the sediment. In Lake Schöhsee, nirS-denitrifiers showed high diversity across the whole water body. Habitat-specific clusters of nirS sequences were observed for the freshwater lakes, while nirK sequences from both freshwater lakes and the Baltic Sea were found in 
common phylogenetic clusters. These results demonstrated differences in the distribution of bacteria containing nirS and those containing nirK indicating that both types of denitrifiers apparently occupy different ecological niches.

Keywords Denitrifying bacteria $\cdot \operatorname{nirK}, \operatorname{nirS}$. Water column - Sediment-water interface . Plußsee, Schöhsee · Baltic Sea

\section{Introduction}

In mictic freshwater lakes, chemical stratification includes a sequence of physically and biologically mediated processes. Warming of the surface water and action of the wind are important parameters for the establishment of a temperature gradient in the water column. The succession of heterotrophic microbial processes in the deeper water layers act as a driving force changing the chemical composition of the water column (Eckert et al. 2002).

The fate of nitrogen-containing compounds in the water column largely depends on the chemical conditions and in particular on the oxygen regime. Under oxic conditions, ammonia is oxidized to nitrate by nitrifying prokaryotes. This happens during winter due to the oxygenation of the water column after mixing. With the onset of stratification in spring, oxygen is consumed and gradually depleted in the hypolimnion. Anoxic conditions lead to the consumption of nitrates as an alternative electron acceptor for respiration in a process called denitrification. Ecologically, denitrification is important because it transforms a biologically available nitrogen form (nitrate) into dinitrogen, which may be lost to the atmosphere (Knowles 1982).

The process of denitrification is catalyzed by four sequentially operating enzymes: nitrate reductase (Nar), nitrite reductase (Nir), nitric oxide reductase (Nor), and nitrous oxide reductase (Nos). Microorganisms possessing these enzymes, largely known as denitrifiers, are found within a wide range of taxonomically distinct groups of Bacteria and Archaea (Zumft 1997; Philippot 2002).

The nitrite reductase (Nir), catalyzing the reduction of $\mathrm{NO}_{2}{ }^{-}$to the gas $\mathrm{NO}$, is considered the key enzyme of denitrification (Zumft 1997). Two evolutionarily distinct nitrite reductases have been reported: the copper-containing NirK encoded by the gene nirK and the cytochrome $c d l$-containing NirS encoded by nirS (Zumft 1997; Philippot 2002). These two enzymes have never been found to coexist in the same denitrifying organism (Coyne et al. 1989). Additionally, the genomic context of the two nir genes is different: while nirS is part of a gene cluster, nirK is generally found isolated in the genome (Philippot 2002).

Recent studies using the nitrite reductase genes as functional molecular markers have significantly contributed to our understanding of the diversity of denitrifying bacteria in a variety of habitats including soils (Avrahami et al. 2002; Priemé et al. 2002; Rösch et al. 2002; Throbäck et al. 2004; Wolsing and Priemé 2004; Sharma et al. 2005; Throbäck et al. 2007), groundwater (Yan et al. 2003), estuarine sediments (Nogales et al. 2002; Santoro et al. 2006), marine sediments (Braker et al. 2000; Liu et al. 2003; Hannig et al. 2006; Falk et al. 2007) and seawater (Tuomainen et al. 2003; Jayakumar et al. 2004; Castro-González et al. 2005; Hannig et al. 2006; Falk et al. 2007; Oakley et al. 2007). Comparatively, there are only few studies on the distribution of denitrifying bacteria in lakes and brackish water habitats. In a previous study on the community composition of denitrifying bacteria in Lake Kinneret (Israel), we have found that denitrifying bacteria carrying the nirK and nirS genes are differentially distributed in the stratified water column. In Lake Kinneret, communities of nirS-denitrifiers were diversified in the epilimnion and nirK-denitrifiers in the anoxic hypolimnion (Junier et al. 2008b).

In the present study, we have compared the distribution of the genes nirK and nirS in two freshwater lakes (Lake Plußsee and Lake Schöhsee) and the brackish Baltic Sea. All of these environments undergo seasonal stratification and form gradients of temperature, salinity, and oxygen. The major questions addressed in this study were (1) Does thermal stratification affect the distribution of nirK and nirS? (2) Are similar distribution patterns observed for denitrifying bacteria carrying different nitrite reductase genes? (3) Do different denitrifying communities exist in freshwater and brackish water habitats?

It could be demonstrated that the main differences in denitrifying community composition, based on analysis of the nirK and nirS genes, occurred between the water column and sediments in each specific 
aquatic environment. Additionally, using these functional genes, ecosystem-specific (i.e., lakes versus brackish water bodies) and habitat-specific (i.e., water-sediment interface versus water column) denitrifying bacterial groups were detected.

\section{Materials and methods}

\section{Sampling sites}

In the eutrophic Lake Plußsee, the pelagic zone was stratified into three layers: (1) the oxic epilimnion roughly corresponding to the photic zone, (2) the metalimnion with steep gradients of oxygen, temperature, and nutrients, and (3) the anoxic hypolimnion with high concentrations of $\mathrm{NH}_{4}-\mathrm{N}$ (Kim et al. 2008). Samples were taken from the epilimnion at $1 \mathrm{~m}$ depth (P1m), metalimnion (4 m depth, P4m), hypolimnion (7 $\mathrm{m}$ depth, P7m), and sediment-water interface (Psedi). Lake Schöhsee is a mesotrophic, stratified lake with oxic conditions in the hypolimnion and an oxic/anoxic gradient at the sediment-water interface. Samples were taken from the epilimnion at $1 \mathrm{~m}$ depth (S1m), metalimnion at $11 \mathrm{~m}(\mathrm{~S} 11 \mathrm{~m})$, hypolimnion at $12 \mathrm{~m}$ depth (S12m), and sediment-water interface (Ssedi). The Baltic Sea off of Kiel Fjord is characterized as mesohaline with salinities ranging from 13.8 to 19.7 practical salinity units (PSU) through the stratified water column. Samples were taken from the oxic surface water at $2 \mathrm{~m}$ depth (B2m), chemocline at $10 \mathrm{~m}$ depth (B10m), microoxic deep water at $20 \mathrm{~m}$ depth (B20m), and sediment-water interface at $27.5 \mathrm{~m}$ depth (Bsedi).

\section{DNA extraction}

Water samples were first filtered through $0.2-\mu \mathrm{m}$ pore size filters (Supor-200, PALL Life Sciences). For each sample, $400 \mathrm{ml}$ of water was filtered through a 47-mm filter. One quarter of the area of the filter was used for the extraction of DNA using the UltraClean Soil DNA kit (MoBio), following the manufacturer's guidelines. Several DNA extractions were pooled for the analysis of each sample. The concentration and quality of DNA was checked by electrophoresis on $0.8 \%$ agarose gels stained with ethidium bromide.
PCR

Nitrite reductase genes were amplified by PCR with the primer pairs $\mathrm{F} 1 \mathrm{aCu}$ and $\mathrm{R} 3 \mathrm{Cu}$ (Hallin and Lindgren 1999) for nirK, and cd3aF (Michotey et al. 2000) and R3cd (Throbäck et al. 2004) for nirS. These primer sets were selected according to the results of a recent re-evaluation of primers for amplifying genes involved in denitrification, in which the above combinations performed the best for cultured strains and environmental samples (Throbäck et al. 2004). Amplification was performed in $50 \mu \mathrm{l}$ volume containing 1-2.5 ng of DNA template, $200 \mathrm{nM}$ of each primer, $1 \times$ PCR buffer, $200 \mu \mathrm{M}$ of each dNTP, $2.5 \mathrm{mM} \mathrm{MgCl} 2,1 \%$ formamide, $0.1 \%$ BSA, and $1 \mathrm{U}$ of $\mathrm{Taq}$ polymerase (Roche). The temperature program started with a 5 min denaturation step at $94^{\circ} \mathrm{C}$, followed by 35 cycles of $1 \mathrm{~min}$ at $94^{\circ} \mathrm{C}, 1 \mathrm{~min}$ at $55^{\circ} \mathrm{C}$ and $1.5 \mathrm{~min}$ at $72^{\circ} \mathrm{C}$. The amplified products were examined on $1.2 \%$ agarose gels by electrophoresis and then purified using a Qiaquick Gel extraction kit (Qiagen) following the manufacturer's instructions.

\section{T-RFLP}

For T-RFLP assays, triplicate PCRs with the labeled primers R3Cd-HEX (nirS) and F1aCu-FAM (nirK) were concentrated and purified using the Qiaquick PCR Purification Kit (Qiagen).

Three T-RFLP profiles were generated in separate reactions from each sample by digestion for $12 \mathrm{~h}$ at $37^{\circ} \mathrm{C}$ with AluI, HaeIII, and MspI (New England) using $10 \mathrm{U}$ of each endonuclease in the manufacturer's reaction buffers. After the precipitation of digested products with ethanol/EDTA, the mixture of ROX and formamide (1:50) was added. Terminal restriction fragments were separated with an automated DNA sequencer, the ABI 3100 Genetic Analyzer (Applied Biosystems).

The lengths of fluorescently labeled terminal restriction fragments (T-RFs) were determined using GeneScan 3.71 software (Applied Biosystems). The results were standardized by peak height as described elsewhere (Wolsing and Priemé 2004). The height of each peak was divided by the average height of all the peaks in each sample. For the T-RFLP profile, a frequency table was prepared with the relative peak height for each detected T-RF in each sample. T-RFs 
obtained with all the enzymes were pooled into a single file for a principal component analysis carried out with Statistica 6 (Statsoft, USA).

\section{Cloning and sequencing}

To avoid sequencing errors introduced by amplification with the Taq polymerase, PCR products for cloning were amplified with the proof-reading $P f u$ DNA polymerase (Promega). PCR conditions were adjusted to the specific conditions of this polymerase by increasing the primer concentration to $25 \mathrm{pmol}$ of each primer in a total reaction volume of $50 \mu \mathrm{l}$ containing $1.5 \mathrm{mM} \mathrm{MgCl}_{2}$, the specific PCR buffer $1 \times\left(20 \mathrm{mM}\right.$ Tris- $\mathrm{HCl} ; 10 \mathrm{mM} \mathrm{KCl} ; 10 \mathrm{mM}\left(\mathrm{NH}_{4}\right)_{2} \mathrm{SO}_{4}$; $2 \mathrm{mM} \quad \mathrm{MgSO}_{4} ; \quad 0.1 \%$ Triton X-100; $1 \mathrm{mg} / \mathrm{ml}$ nuclease-free BSA) and $200 \mu \mathrm{M}$ of each dNTP. The PCR program was also adjusted and consisted of an initial denaturation at $95^{\circ} \mathrm{C}$ for $2 \mathrm{~min}$, hot start at $80^{\circ} \mathrm{C}$, followed by 25 cycles of denaturation at $95^{\circ} \mathrm{C}$ for $30 \mathrm{~s}$, annealing at $55^{\circ} \mathrm{C}$ for $30 \mathrm{~s}$ and extension at $73^{\circ} \mathrm{C}$ for $3 \mathrm{~min}$. The final extension was performed at $73^{\circ} \mathrm{C}$ for $5 \mathrm{~min}$. Duplicate PCRs were pooled and concentrated on a Multiscreen plate (Millipore), and after electrophoresis on agarose gel the right sized products were cut and eluted using the QIAGEN Kit (Qiagen). The Zero Blunt PCR cloning kit (Invitrogen) was used for cloning according to the manufacturer's guidelines.

From each sample that was cloned, 48 clones were randomly selected and checked for inserts of the expected size by PCR with the plasmid-specific primers M13F/M13R and agarose gel electrophoresis. For the screening of the clones containing an insert with the expected size, one-shot sequencing with the M13F primer was performed using the BigDye Terminator v3.1 Cycle Sequencing Kit. Sequences were analyzed with an ABI 3100 Genetic Analyzer (Applied Biosystems) according to the manufacturer's recommendations. The resulting nucleotide sequences were checked with BLASTX (Altschul et al. 1997) on the NCBI website. (http://www.ncbi. nlm.nih.gov/BLAST/). Only clones carrying sequences that matched recognized nirS and nirK sequences in BLAST were considered for further analysis. The sequences obtained in this study were deposited in GenBank under the accession numbers DQ337713DQ337812 and EF615209-EF615414 for nirK and
DQ337813-DQ337925 and EF615415-EF615570 for $n i r S$.

Phylogenetic, diversity, and statistic analyses of the clone libraries

Phylogenetic analyses were performed as described in Junier et al. (2008b) using the software ARB (http://www.arb-home.de). The DOTUR program (Schloss and Handelsman 2005) was used for rarefaction analysis to compare the nirK and nirS sequence diversity within each clone library. Operational taxonomic units (OTUs) were defined as sequence groups in which sequences differed by $\leq 5 \%$. This threshold was chosen according to a previous study of nirS and nirK diversity (Santoro et al. 2006) suggesting that the $5 \%$ cutoff represents an appropriate balance between emphasizing small but population-defining genetic differences and the likelihood of functional differences in enzyme activity. The web version of the program Libshuff (http://libshuff.mib.uga.edu/) was used to assess statistical differences between the clone libraries obtained. For simulation of T-RFs lengths in the clones, the program TRiFLe was used (Junier et al. 2008a).

\section{Results}

T-RFLP analysis of nirK and nirS

Relative abundance of T-RFs

PCR products of nirK (470 bp) and nirS (410 bp) were obtained from all the samples. Analysis of T-RFLP patterns showed that from the three enzymes used, the digestion with HaeIII produced the highest number of different T-RFs for both genes (19 T-RFs for $n i r K$ and 20 for $n i r S$ ), compared to AluI and MspI (13 and 16 for nirK; 15 and 17 for nirS). Therefore, the relative abundances of individual T-RFs after HaeIII digestion were used for further considerations (Supplementary Figs. 1 and 2).

Different T-RFLP nirK patterns were obtained in all three habitats (Supplementary Fig. 1). Only a few T-RFs (174 and $279 \mathrm{bp}$ ) were observed in more than one sampling site. The T-RFs 35, 41, and $205 \mathrm{bp}$ were detected in both lakes, and the T-RF $240 \mathrm{bp}$ was 
found in the Baltic Sea and Schöhsee. In all three habitats, the T-RF patterns from sediment samples were clearly different from those in the water column. Patterns from sediments in the Baltic Sea and Plußsee were not dominated by any particular T-RF, while in Schöhsee the T-RF 143 bp represented more than $60 \%$ of the fluorescence.

A higher proportion of T-RFs was shared between different samples from the same environment. In the Baltic Sea, the relative contribution of T-RFs 231, 279,294 , and 335 bp changed with depth in the water column. Likewise, in Schöhsee a similar shift in the abundance of the T-RFs 41, 205, and $240 \mathrm{bp}$ was observed. The T-RF $111 \mathrm{bp}$ was unique to Plußsee and was detected there at depths of 1, 4, 7 m, and in the sediment.

Despite the fact that T-RFLP is an appropriate approach for community profiling, it has as a drawback the impossibility for directly sequencing the different T-RFs in order to confirm their identity. One alternative to this is the simulation of the T-RFs from a database of sequences such as, for example, clone libraries obtained from the samples used on the T-RFLP. This analysis was carried out using the clone libraries prepared in this study (see below). For nirK, a total of 22 different T-RFs were obtained after the simulation (Supplementary Fig. 3). From those, nine out of 19 T-RFs could be identified in the samples. These T-RFs corresponded to clones from the clusters VI (subclusters a and f) and VII (subclusters a and b). Unfortunately, there is no a direct correlation between the frequency of the clones and the presence of a particular T-RF in the samples. For example, the most frequent T-RF in the clones (T-RF $96 \mathrm{bp}$ ) was not observed in the samples.

The T-RFLP patterns of nirS contained more T-RFs than those of nirK (Supplementary Fig. 2).
The smallest T-RF 36 bp was common to all samples, but Plußsee $7 \mathrm{~m}$ and Schöhsee $14 \mathrm{~m}$. Similarly, the T-RFs 66, 136, and $147 \mathrm{bp}$ appeared in all three environments. The T-RFs 130, 222, 271, and $407 \mathrm{bp}$ appeared in the Baltic Sea and Plußsee, whereas the Baltic Sea and Schöhsee shared the T-RFs 53, 72, 91, 176, 301, and $372 \mathrm{bp}$. The T-RF $160 \mathrm{bp}$ was detected only in the two lakes. T-RF 102 bp was observed only in the Baltic Sea and T-RF 333 bp in Plußsee. No unique T-RFs were found in Schöhsee. In the Baltic Sea, none of the samples were dominated by any particular T-RF, while one T-RF was dominant in Plußsee $7 \mathrm{~m} \mathrm{(60} \mathrm{bp)} \mathrm{and} \mathrm{Schöhsee} 1$ and $12 \mathrm{~m}$ (36 bp).

As mentioned for nirK, only a small fraction of the T-RFs in the samples were observed after the simulation using the nirS clone libraries. In the clones, 31 different T-RFs were observed. From those, $11 \mathrm{~T}$-RFs were also observed in the patterns from the samples. These $11 \mathrm{~T}$-RFs represented five clusters (I, IV, V, VI, and VIII). As it was observed for nirK, there was no correlation between the frequency of clones and the T-RFs in the samples, limiting their identification.

\section{Principal component analysis (PCA) of T-RFLP of nirK and nirS}

Although specific T-RFs could not be used for the identification of specific groups of sequences, the results of the T-RFLP data were used to analyze the relationship between the samples. A PCA of T-RFLP for nirK and nirS with the combined results of the three restriction enzymes was carried out (Fig. 1 and Supplementary Fig. 4). According to the PCA of nirK- derived T-RFLPs, the nirK T-RFs profiles in the sediment were different from those in
Fig. 1 Principal component analysis (PCA) of T-RFLP of $\operatorname{nirK}(\mathbf{a})$ and $\operatorname{nirS}$ (b) from samples of the Baltic Sea and lakes Plußsee and Schöhsee from all the digestions combined
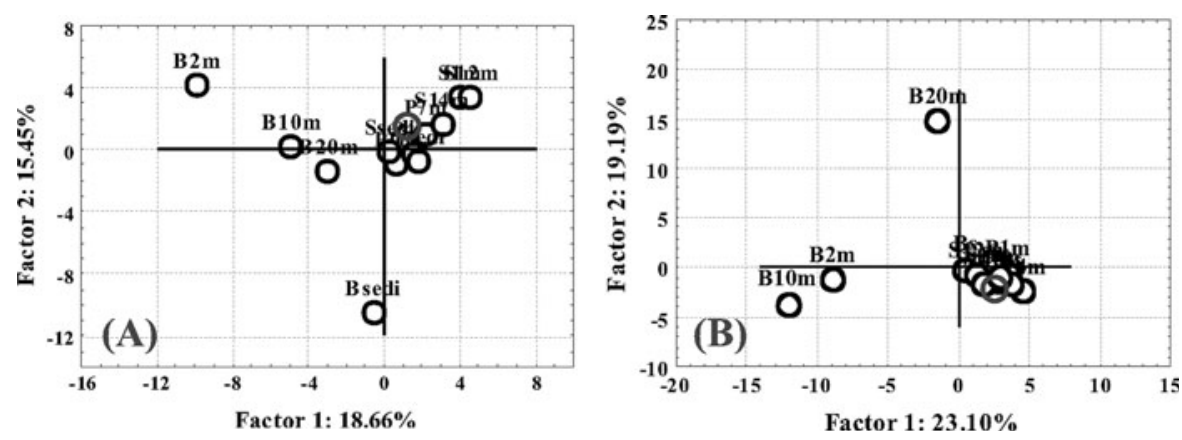
the water column in all three habitats (Supp. Fig. 4AC). In the Baltic Sea water column, the nirK T-RFLP profiles at $10 \mathrm{~m}$ depth were intermediate to those at 2 and $20 \mathrm{~m}$. In the lakes, nirK T-RFLP profiles from 1 and $4 \mathrm{~m}$ depth of Plußsee and from 11, 12, and $14 \mathrm{~m}$ depth of Schöhsee formed a common group. The combined analysis of all the samples showed that nirK T-RFLP profiles in the two lakes were similar to each other but clearly separated from those in the Baltic Sea (Fig. 1a).

PCA of nirS-derived T-RFs showed characteristic nirS profiles in the Baltic Sea at $20 \mathrm{~m}$, in Plußsee at $7 \mathrm{~m}$ and in Schöhsee at $14 \mathrm{~m}$ depth that were different from other samples by the presence of PC1 (Supp. Fig. 3A-C). In the combined analysis of the all the samples, nirS T-RFLP profiles in the two lakes were similar to each other but clearly separated from those in the water column of the Baltic Sea. Interestingly, the T-RFs pattern of the water-sediment interface sample in the Baltic Sea grouped with the samples from the freshwater lakes, including those from the water-sediment interface (Psedi and Ssedi) (Fig. 1b).

Clone libraries and sequence analysis of nirK and nirS PCR products

\section{Clone libraries}

Based on the PCA results of the T-RFLP, nine samples for nirK and ten samples for nirS were selected to generate clone libraries in order to cover most of the diversity seen in the entire set of samples. These include the sediments from the three habitats, samples from 2 and $20 \mathrm{~m}$ depth of the Baltic Sea, samples from 1 and $7 \mathrm{~m}$ depth of Plußsee and samples from 1 and $12 \mathrm{~m}$ depth of Schöhsee for both nirK and nirS genes. In addition, the sample from $14 \mathrm{~m}$ depth of Schöhsee was chosen for cloning of nirs because it was different from the other samples in the PCA.

A total of 305 nirK and 268 nirs clones with an insert of 470 and $473 \mathrm{bp}$ for nirK and 410-425 bp for nirS were sequenced (Table 1). Almost all clonal sequences were related to uncultured denitrifying bacteria as revealed by BLASTX (similarities ranging from 74 to $100 \%$ for NirK and from 59 to $96 \%$ for $\mathrm{NirS}$ ). Only two nirK sequences were $100 \%$ identical with NirK from the cultured denitrifier Ochrobactrum sp. 2FB10 (AY078249).

nirK phylogeny

All nirK sequences from this study belonged to six out of eight clusters in the phylogenic tree obtained (Fig. 2). The clusters I-VI correspond to those described by Priemé et al. (2002) and Junier et al. (2008b). No clones were found in clusters III and IV. Two new clusters, VII and VIII, were identified in this study. The majority of the sequences fell into clusters VI (130) and VII (122). Based on the identity with NirK from a denitrifying strain of Rhodobacter sphaeroides that was isolated from polluted water in a Japanese pond (Satoh et al. 1976), sequences in cluster VII could be divided into at least two subclusters: sequences in subcluster VIIa were $67-72 \%$ similar to each other, while those in subcluster VIIb were 58-60\% similar. Subcluster VIIa contained a few sequences from a wide range of environments, such as Baltic Sea (Tuomainen et al. 2003), northwestern Mexican sediment (Liu et al. 2003), activated sludge (Throbäck et al. 2004), Huntington State Beach, California (Santoro et al. 2006), and Lake Kinneret (Junier et al. 2008b). In contrast, the smaller subcluster VIIb contained only sequences from this study.

Cluster VI included NirK from Roseovarius sp. 217 (Acc. No. NZ_AAMV01000015) isolated from surface seawater collected near Plymouth, England (Schäfer et al. 2005) and environmental sequences that were $65-86 \%$ identical to NirK from this bacterium. Cluster VI was further divided into two subclusters VIa and VIb, by considering the origin of sequences. Subcluster VIa included the sequences from Baltic Sea and Lake Plußsee that were closely related with those from Huntington State Beach, California (Santoro et al. 2006). Sequences in subcluster VIb were associated with those from Lake Kinneret (Junier et al. 2008b) and from an Agcontaminated soil (Throbäck et al. 2007).

Cluster I contained three subclusters (Ie, Ii, and Ik) with sequences from the water column of the Baltic Sea, and the $12 \mathrm{~m}$ depth and sediment samples of Lake Schöhsee, all of which were closely related to sequences from soil (Priemé et al. 2002; Throbäck et al. 2004; Wolsing and Priemé 2004). Similarly, cluster II included sequences from the water column 
Table 1 Summary of nirK and nirS clone libraries in the different sampling sites including the number of clones, unique clones and estimated number of OTUs and richness by Chao1 using DOTUR program. OTUs and Chao1 value were defined by $\leq 2$ and $5 \%$

\begin{tabular}{|c|c|c|c|c|c|}
\hline Environment & Depth (m) & $\begin{array}{l}\text { No. of } \\
\text { clones }\end{array}$ & $\begin{array}{l}\text { No. of unique } \\
\text { clones }\end{array}$ & $\begin{array}{l}\text { No. of OTUs } \\
(2 \% / 5 \%)\end{array}$ & $\begin{array}{l}\text { Chao1 value } \\
(2 \% / 5 \%)\end{array}$ \\
\hline \multicolumn{6}{|l|}{ nirK } \\
\hline \multirow[t]{3}{*}{ Baltic Sea } & 2 & 32 & 14 & $12 / 12$ & $16 / 16$ \\
\hline & 20 & 41 & 7 & $5 / 5$ & $8 / 8$ \\
\hline & Surface of sediment & 44 & 20 & $15 / 14$ & $33 / 21$ \\
\hline \multirow[t]{3}{*}{ Plußsee } & 1 & 40 & 16 & $10 / 9$ & $11 / 9$ \\
\hline & 7 & 32 & 13 & $12 / 10$ & $21 / 15$ \\
\hline & Surface of sediment & 18 & 13 & $8 / 6$ & $9 / 6$ \\
\hline \multirow[t]{3}{*}{ Schöhsee } & 1 & 20 & 8 & $6 / 6$ & $12 / 12$ \\
\hline & 12 & 38 & 17 & $9 / 9$ & $12 / 12$ \\
\hline & Surface of sediment & 40 & 14 & $9 / 6$ & $9 / 6$ \\
\hline \multicolumn{6}{|l|}{ nirs } \\
\hline \multirow[t]{3}{*}{ Baltic Sea } & 2 & 4 & 2 & $2 / 2$ & $2 / 2$ \\
\hline & 20 & 2 & 2 & $2 / 2$ & $2 / 2$ \\
\hline & Surface of sediment & 24 & 18 & $19 / 17$ & $79 / 56$ \\
\hline \multirow[t]{3}{*}{ Plußsee } & 1 & 11 & 8 & $7 / 7$ & $8 / 8$ \\
\hline & 7 & 33 & 5 & $6 / 5$ & $9 / 6$ \\
\hline & Surface of sediment & 37 & 26 & $29 / 27$ & $179 / 165$ \\
\hline \multirow[t]{4}{*}{ Schöhsee } & 1 & 23 & 13 & $14 / 11$ & $17 / 13$ \\
\hline & 12 & 41 & 22 & $17 / 15$ & $45 / 38$ \\
\hline & 14 & 47 & 17 & $11 / 10$ & $14 / 13$ \\
\hline & Surface of sediment & 47 & 39 & $33 / 29$ & $46 / 38$ \\
\hline
\end{tabular}

of all three habitats that were related to those from diverse environments. Cluster V contained sequences from Schöhsee water-sediment interface, and cluster VIII those from Baltic Sea water-sediment interface, which were related to nirK from Huntington State Beach, California (Santoro et al. 2006).

\section{nirS phylogeny}

Ten clusters were identified in the phylogenetic tree of nirS (Fig. 3). Clusters I-V were known from previous studies (Yan et al. 2003); clusters VI-X were new from this study. Most of the nirS sequences (88) belonged to cluster I, which includes sequences from all samples of both lakes, but none from the Baltic Sea. These sequences were divided into five subclusters. Subcluster Ia contained sequences from Lake Schöhsee and one other from arable soil (Acc. No. AY583409) (Throbäck et al. 2004). This purely environmental subcluster is only distantly related to cultured denitrifying bacteria. Subcluster Ib,
Fig. 2 Phylogenetic tree of nirK gene, based on 158 deduced amino acids, constructed by neighbor-joining method in ARB with aniA from Neisseria gonorrhoeae (M97926) as the outgroup. Clones from this study are shown in bold and designated as $B$, Baltic Sea; $P$, lake Plußsee; $S$, lake Schöhsee and followed by depth. Sedi $=$ sample from sediment-water interface. The values in parentheses are the number of identical clones. Bootstrap values for 1,000 replicates are indicated at the branch points by circles: black (100\%), gray (95-99\%) and white (90-94\%). PNWS, Pacific Northwest sediment (Braker et al. 2000); RCES, River Colne estuary sediment (Nogales et al. 2002); FUWS, forested upland and wetland soil (Priemé et al. 2002); SDAC, incubated soil with different ammonia concentration (Avrahami et al. 2002); NWMS, northwestern Mexico sediment (Liu et al. 2003); NUCG, nitrateand uranium-contaminated groundwater (Yan et al. 2003); BSCB, Baltic Sea cyanobacterial bloom (Tuomainen et al. 2003); MWTS, metallurgic wastewater treatment systems (Yoshie et al. 2004); $A S A F$, arable soil receiving artificial fertilizer (Wolsing and Priemé 2004); ASWC, Arabian Sea water column (Jayakumar et al. 2004); ARSO (arable soil), ACSL (activated sludge) and PESO (peat soil) (Throbäck et al. 2004); OESP, OMZ in the eastern South Pacific (Castro-González et al. 2005); HSBC, Huntington State Beach, California (Santoro et al. 2006); BSWC, Baltic Sea water column (Hannig et al. 2006); AGCS, Ag-contaminated soil (Throbäck et al. 2007); LKWC, Lake Kinneret water column (Junier et al. 2008b); BSSZ, Black Sea suboxic zone (Oakley et al. 2007) 


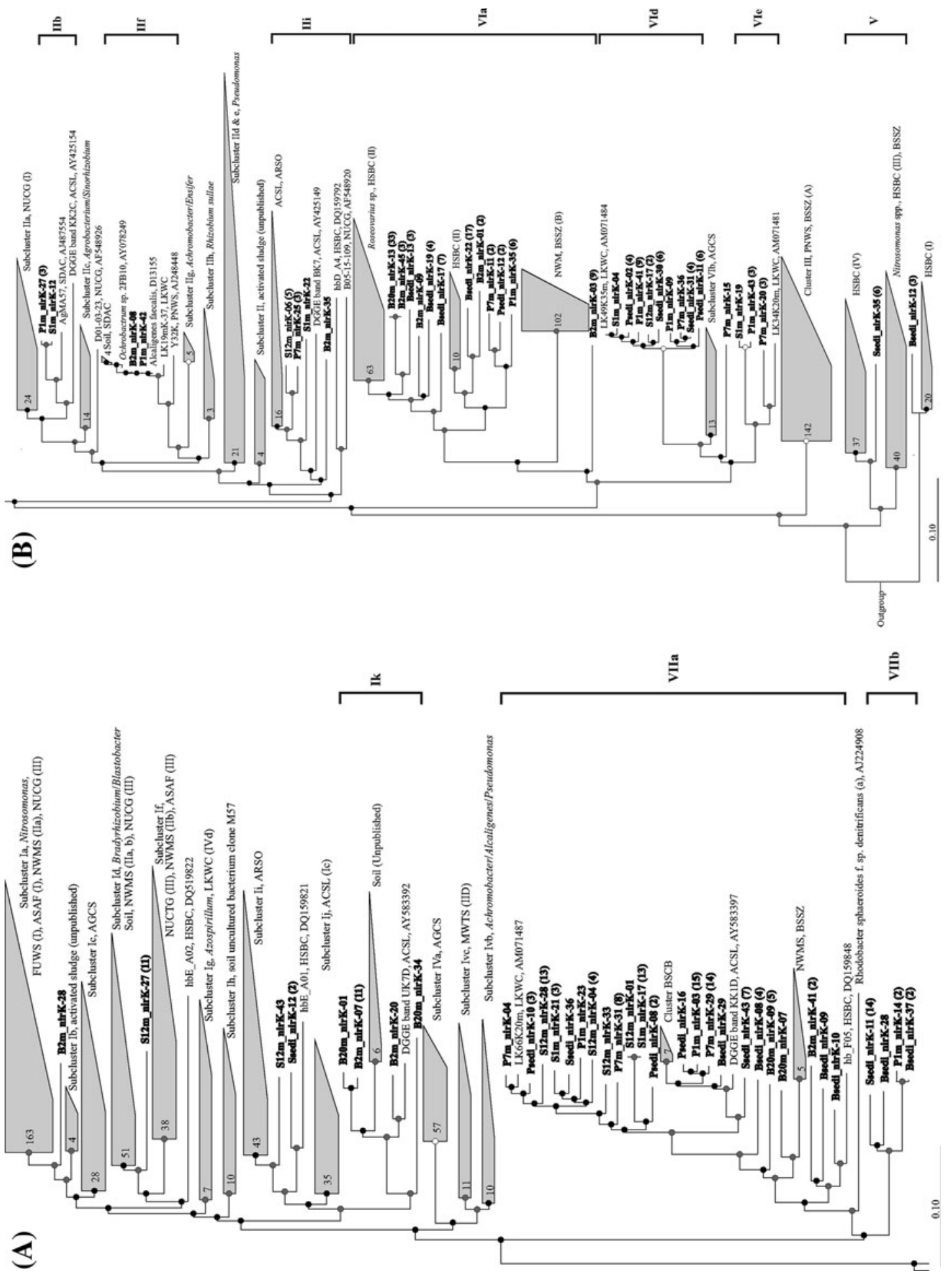



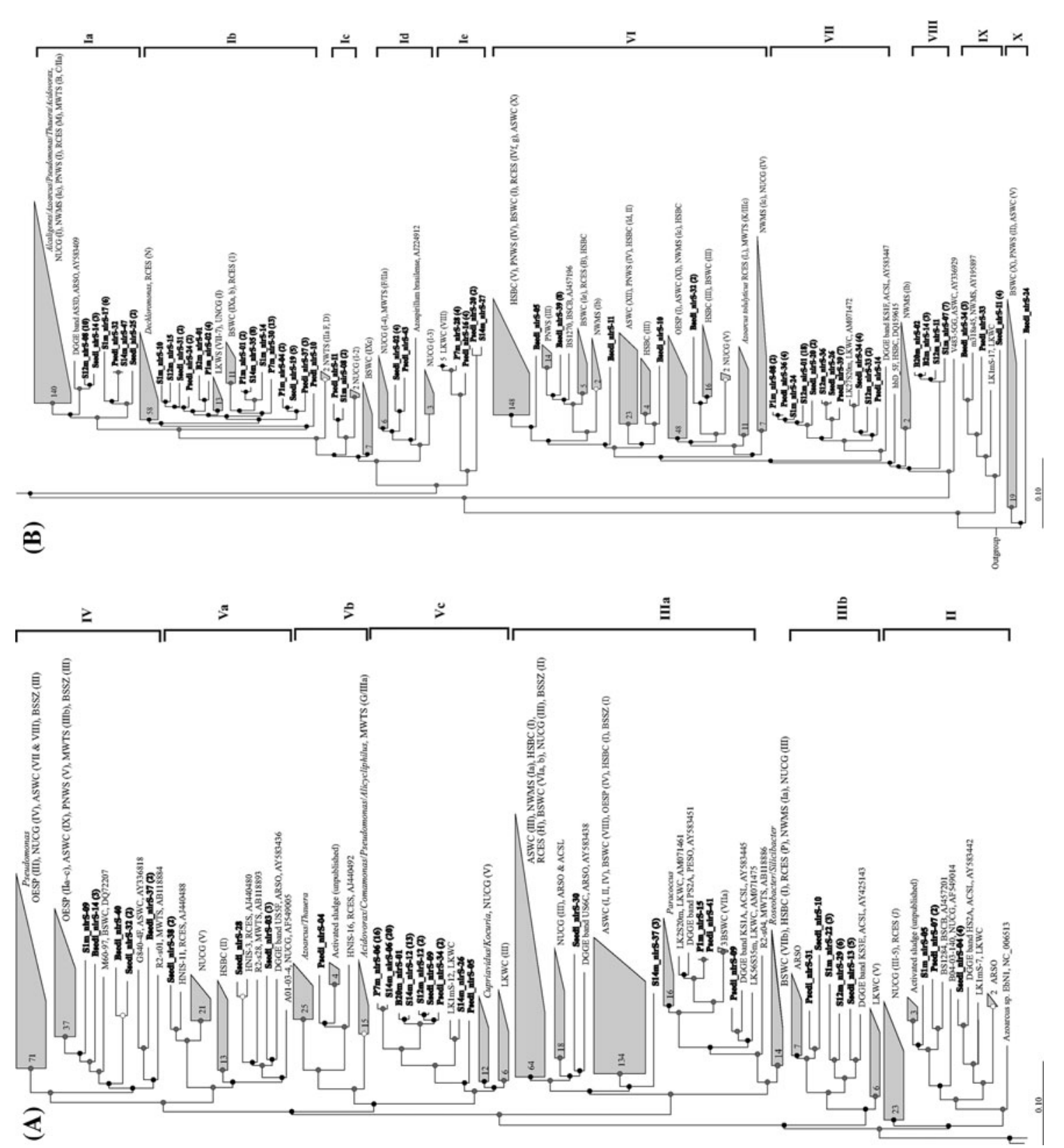

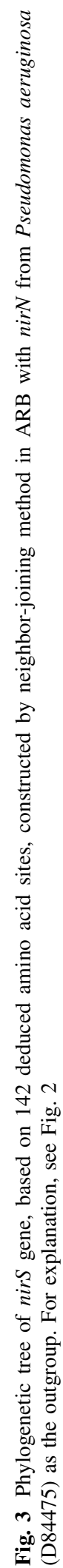


containing NirS from Dechloromonas spp., also includes sequences from the water column of Lake Kinneret (Junier et al. 2008b), the Baltic Sea (Hannig et al. 2006), and sediment of River Colne estuary (Nogales et al. 2002). Sequences in the smaller subclusters Ic and Id were related to those from nitrate- and uranium-contaminated groundwater (Yan et al. 2003). Subcluster Ie is a lake-specific cluster with sequences from Lake Plußsee and Lake Kinneret (Junier et al. 2008b) and one sequence from Lake Schöhsee (S14m_nirS_27).

Sequences from both lakes were also found in clusters V and VII. Subcluster Vc was dominated by sequences from $7 \mathrm{~m}$ of Lake Plußsee and $14 \mathrm{~m}$ of Lake Schöhsee. Sequences in subcluster Vc were closely related to some sequences from Lake Kinneret and with NirS from Cupriavidus necator (AM230890) ( $<85 \%$ identity). Cluster VII was comprised of sequences from water and sediment of Lake Plußsee and Schöhsee, from water of Lake Kinneret, from arable soil, and from activated sludge, at $\leq 74 \%$ identity with the NirS from Azoarcus tolulyticus (AY078272).

\section{Rarefaction analysis of nirK and nirS sequences}

Rarefaction analysis carried out using 5\% dissimilarity as cutoff for OTU definition (Fig. 4) showed that nirS-denitrifiers are expected to be more diverse than nirK-denitrifiers, especially in the sediments. However, saturation was not reached in either case. The highest number of OTUs for nirK was obtained in the sample from the Baltic Sea sediment with 14 OTUs followed by the water sample ( $2 \mathrm{~m}$ depth) of the Baltic Sea with 12 OTUs. The lowest number of OTUs for nirK was obtained in Baltic Sea $20 \mathrm{~m}$ with five OTUs. Diversity in both lakes is expected to be at an intermediate level. In the case of nirS, higher diversity was found in samples from sediments when compared to the water column of all three environments. Among the sediment samples, a higher number of OTUs was detected in Schöhsee (29), followed by Plußsee (27) and the Baltic Sea (17).

\section{PCA of nirK and nirS sequences}

The differentiation of the denitrifying communities in the three environments and within different habitats was also tested by PCA based on the composition of
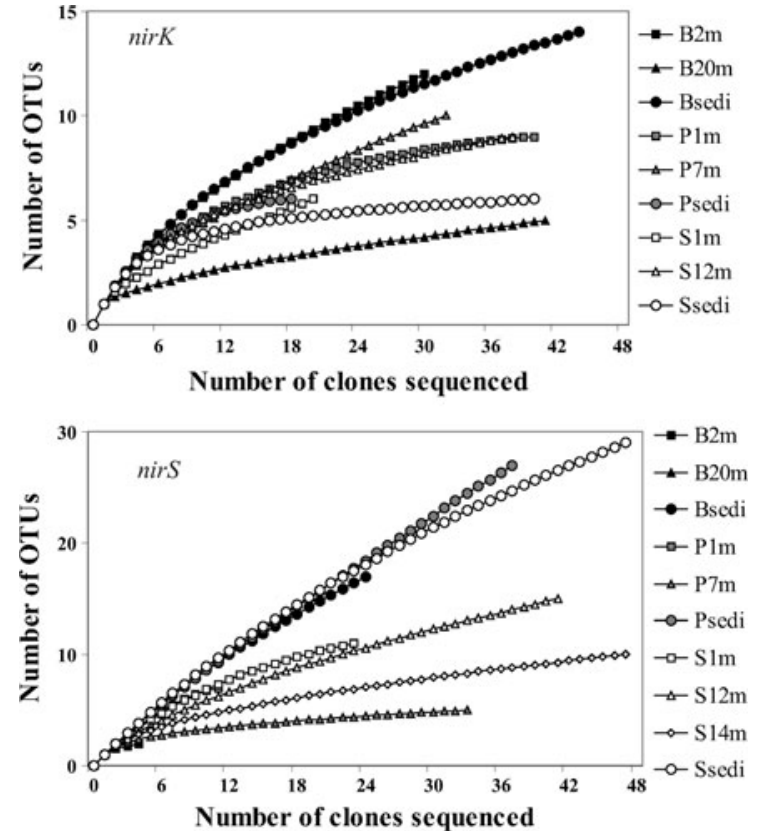

Fig. 4 Rarefaction curves indicating nirK and nirS diversity in clone libraries derived from each environment. OTUs were defined as groups of sequences differing by $\leq 5 \%$ at the DNA level

individual clone libraries (Fig. 5). In the case of nirK, the three clone libraries from the Baltic Sea were clearly separated from all other libraries from lakes Plußsee and Schöhsee (Fig. 5a). This was consistent with the PCA based on the T-RFs patterns (Fig. 1a). However, a statistically significant difference based on the coverage analysis of the clone libraries (Table 2) was only obtained for the library from the water-sediment interface in the Baltic Sea compared to the corresponding samples from the Baltic Sea water column and Lake Schöhsee at $12 \mathrm{~m}$ depth.

Sediment-water interface libraries from the three environments were differentiated in the analysis based on the nirS gene (Fig. 5b). In the PCA, libraries from the water column of the three environments formed a group, although the libraries from lake Plußsee at $1 \mathrm{~m}$ depth and lake Schöhsee at $12 \mathrm{~m}$ depth were slightly separated from this group (Fig. 5b). PCA based on sequences in the clone libraries differed considerably from PCA based on T-RFs patters (Fig. 1b). This is consistent with the fact that few nirS sequences were detected in the samples from the water column of the Baltic Sea, suggesting that PCA results based on T-RFs analysis 
Fig. 5 Principal component analysis (PCA) of clone libraries of nirK (a) and $\operatorname{nirS}$ (b) from samples of the Baltic Sea and lakes Plußsee and Schöhsee

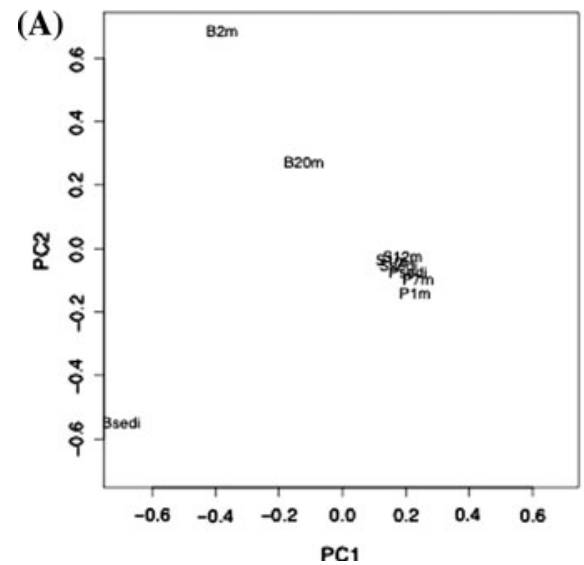

may be biased due to the presence of un-specific PCR amplification. Differentiation of the clone libraries from the water-sediment interface samples was statistically significant (Table 2). This was especially true for the water-sediment interface libraries from Lake Schöhsee and the Baltic Sea, for which a significant difference was observed with eight and five out of the nine libraries, respectively.

Table 2 Population $P$ values for comparison of nirK and nirS clone libraries determined using the Cramer-von Mises statistic, implemented in LIBSHUFF

\begin{tabular}{|c|c|c|c|c|c|c|c|c|c|c|c|c|}
\hline \multirow[t]{2}{*}{ Gene } & \multirow{2}{*}{$\begin{array}{l}\text { Sample for } \\
\text { homology } \\
\text { library (x) }\end{array}$} & \multirow[t]{2}{*}{ Clones } & \multicolumn{10}{|c|}{$P$ values for comparison of heterologous libraries $(Y)$ with $X$} \\
\hline & & & $\mathrm{B} 2 \mathrm{~m}$ & $\mathrm{~B} 20 \mathrm{~m}$ & Bsedi & P1m & P7m & Psedi & S1m & $\mathrm{S} 12 \mathrm{~m}$ & Ssedi & $\mathrm{S} 14 \mathrm{~m}^{\mathrm{a}}$ \\
\hline \multirow[t]{9}{*}{ nirK } & B2 $\mathrm{m}$ & 32 & & 0.158 & 0.177 & 0.099 & 0.643 & 0.164 & 0.099 & 0.384 & 0.035 & \\
\hline & B20 m & 41 & 0.623 & & 0.015 & 0.043 & 0.218 & 0.850 & 0.409 & 0.117 & 0.071 & \\
\hline & Bsedi & 44 & 0.001 & 0.001 & & 0.166 & 0.201 & 0.391 & 0.102 & 0.009 & 0.385 & \\
\hline & $\mathrm{P} 1 \mathrm{~m}$ & 40 & 0.908 & 0.320 & 0.416 & & 0.460 & 0.726 & 0.195 & 0.483 & 0.248 & \\
\hline & P7 m & 32 & 0.959 & 0.215 & 0.488 & 0.383 & & 0.386 & 0.032 & 0.058 & 0.153 & \\
\hline & Psedi & 18 & 0.725 & 0.482 & 0.810 & 0.749 & 0.429 & & 0.695 & 0.270 & 0.570 & \\
\hline & $\mathrm{S} 1 \mathrm{~m}$ & 20 & 0.788 & 0.197 & 0.192 & 0.729 & 0.408 & 0.246 & & 0.010 & 0.062 & \\
\hline & $\mathrm{S} 12 \mathrm{~m}$ & 38 & 0.454 & 0.504 & 0.721 & 0.518 & 0.481 & 0.604 & 0.657 & & 0.062 & \\
\hline & Ssedi & 40 & 0.835 & 0.153 & 0.274 & 0.447 & 0.647 & 0.033 & 0.261 & 0.296 & & \\
\hline \multirow[t]{10}{*}{$n i r S$} & B2 m & 4 & & 0.466 & 0.091 & 0.201 & 0.112 & 0.259 & 0.269 & 0.043 & 0.484 & 0.059 \\
\hline & B20 m & 2 & 1.000 & & 0.011 & 0.397 & 0.554 & 0.159 & 0.606 & 0.190 & 0.838 & 0.012 \\
\hline & Bsedi & 24 & 0.295 & 0.456 & & 0.176 & 0.001 & 0.072 & 0.003 & 0.001 & 0.001 & 0.001 \\
\hline & $\mathrm{P} 1 \mathrm{~m}$ & 11 & 0.677 & 0.746 & 0.502 & & 0.068 & 0.807 & 0.890 & 0.915 & 0.886 & 0.123 \\
\hline & P7 m & 33 & 0.264 & 0.680 & 0.654 & 0.115 & & 0.026 & 0.764 & 0.188 & 0.001 & 0.792 \\
\hline & Psedi & 37 & 0.757 & 0.979 & 0.007 & 0.198 & 0.922 & & 0.165 & 0.181 & 0.018 & 0.042 \\
\hline & $\mathrm{S} 1 \mathrm{~m}$ & 23 & 0.356 & 0.136 & 0.002 & 0.002 & 0.494 & 0.905 & & 0.75 & 0.001 & 0.507 \\
\hline & $\mathrm{S} 12 \mathrm{~m}$ & 47 & 0.848 & 0.939 & 0.063 & 0.292 & 0.420 & 0.214 & 0.807 & & 0.001 & 0.461 \\
\hline & Ssedi & 47 & 0.001 & 0.039 & 0.001 & 0.001 & 0.001 & 0.001 & 0.001 & 0.001 & & 0.001 \\
\hline & $\mathrm{S} 14 \mathrm{~m}$ & 40 & 0.540 & 0.693 & 0.482 & 0.057 & 0.802 & 0.790 & 0.891 & 0.713 & 0.001 & \\
\hline
\end{tabular}

Analyses were carried out using the web interface of the program (http://libshuff.mib.uga.edu/). Boldface values indicate significant $P$ values $(P \leq 0.025)$ after Bonferroni correction for pairwise comparisons of 2 clone libraries. Libraries are distinct from one another if either of the comparisons ( $X$ versus $Y$ and $Y$ versus $X$ ) is significant

a Sample S14m was only included in the nirS analysis 


\section{Discussion}

Distribution of denitrifying communities in stratified water bodies

The distribution of denitrifying bacterial communities responds to a variety of environmental factors including oxygen (Liu et al. 2003; Jayakumar et al. 2004; Castro-González et al. 2005; Hannig et al. 2006), nitrates (Liu et al. 2003), DOC, inorganic nitrogen and salinity gradients (Taroncher-Oldenburg et al. 2003), as well as nitrite and sulfide concentrations (Jayakumar et al. 2004; Hannig et al. 2006). Factors affecting the distribution of denitrifying communities in stratified lakes are less well known. In lakes Plußsee and Schöhsee, the distribution of denitrifying bacteria apparently is correlated to the different nutrient status in the two lakes. Lake Plußsee is an eutrophic freshwater lake that has a stable thermal stratification during summer with anoxia in the hypolimnion (Overbeck and Chróst 1994). Lake Schöhsee is a mesotrophic freshwater lake with oxic conditions down to the sediment-water interface and low algal biomass (Rai et al. 1997; Aberle and Wiltshire 2006).

In lake Plußsee, nirK- and nirS-denitrifiers appear to occupy specific habitats: nirK-denitrifiers thrive in the water column, while nirS-denitrifiers do so at the water-sediment interface. In contrast, in lake Schöhsee both nirK- and nirS-denitrifiers were diversified in both the water column and the sediment-water interface. In Lake Schöhsee, oxygen and other nutrients could be delivered from the water column down to the sediment-water interface explaining the richness of different kinds of denitrifying bacteria in all habitats. In comparison, in Lake Plußsee, the epilimnion, hypolimnion, and sediment are less interconnected probably explaining the exclusion of different types of denitrifiers. This sort of distribution has been also observed in nitrate-contaminated groundwater (Yan et al. 2003) and the water column of Lake Kinneret (Junier et al. 2008b).

Different studies analyzing denitrifying bacterial communities in the Baltic Sea, the world's largest brackish environment, suggest relatively low diversity of nirS-denitrifying bacteria and have failed to recover nirK sequences from the water column and sediments (Brettar et al. 2001; Hannig et al. 2006; Falk et al. 2007). However, recently a study in the suboxic zone of the water column (Oakley et al. 2007) showed higher variation in nirK compared to nirS. We also detected a fairly diverse assemblage of nirK-denitrifiers through the water body of the Baltic Sea. These new sequences enlarge our knowledge of aquatic nirK-denitrifiers, which are so far poorly represented in public databases. In the past, some studies have failed to amplify nirK from aquatic samples (e.g., Castro-González et al. 2005), suggesting that nirK-denitrifiers may be dominant in terrestrial environments. However, the use of new primers enabled the amplification of aquatic nirK sequences and is contributing to change our view on the distribution of nirK-denitrifiers.

Surprisingly, despite the same sampling/analysis effort and treatment, nirS-denitrifiers could not be amplified in samples of the Baltic Sea water column. This result is unexpected considering that nirSdenitrifiers have been frequently found in estuarine and marine habitats (Braker et al. 2000; Liu et al. 2003; Jayakumar et al. 2004; Santoro et al. 2006) and have been reported previously in the water column and sediments of the Baltic Sea (Brettar et al. 2001; Hannig et al. 2006; Falk et al. 2007). Therefore, we consider the restricted number of nirS sequences obtained here to reflect the actual situation at the sampling time, but not as an indication of the absence of nirS-denitrifiers in the water column of the Baltic Sea.

It should be noted that considering the physiological diversity of denitrifying bacteria, other factors, rather than their ability to perform denitrification with either of the two known nitrite reductases, may also affect distribution significantly. However, the differential distribution of nirK- and nirS-containing denitrifiers found in the three environments studied here strongly argues for the denitrifying metabolism to determine their distribution pattern.

On the other hand, the habitat also appears to play a very significant role. A differentiation of the nirSdenitrifying communities from the sediments and those from the water column was demonstrated in all three environments based on the analysis of the clone libraries. T-RFLP data also suggest this can be the case for nirk, although PCA data based on clone libraries did not show the same trend. Similar results have been obtained in the water column of the Gotland Basin and coastal sediments of the Baltic Sea based on the analysis of nirS (Hannig et al. 2006; Falk et al. 2007), suggesting that the sediments 
represent a very particular habitat for denitrifying bacteria independently of the type of nitrite reductase they contain.

Environment-specific denitrifying communities

In a previous study in Lake Kinneret, results from clone libraries of the nirS and nirK genes showed that freshwater denitrifying communities differed from those of marine habitats and coastal aquifers, suggesting a differentiation of marine and purely freshwater denitrifying bacteria. This was especially true for the nirS gene (Junier et al. 2008b). Similarly, phylogenetic analysis of nirS sequences from the Baltic Sea and other marine habitats from all over the world indicated the grouping of denitrifying communities according to their habitat (Falk et al. 2007). In the present study, the nirS sequences for the Baltic Sea were clustered together with nirS from other brackish and marine habitats (Braker et al. 2000; Liu et al. 2003; Tuomainen et al. 2003; Jayakumar et al. 2004; Hannig et al. 2006; Santoro et al. 2006) and differed from those observed in the lakes Schöhsee and Plußsee. Specific groups of freshwater nirS sequences were also detected: cluster I (which includes sequences from all samples of both lakes, but none from the Baltic Sea), subcluster Ie (which also included sequences from Lake Kinneret), and clusters V and VII.

In the case of nirK, we found common sequences for the three aquatic environments studied here. These sequences grouped into clusters VI and VII, which may so far be considered specific for freshwater to brackish habitats, and that also included sequences from Lake Kinneret (Junier et al. 2008b) and a coastal aquifer at Huntington Beach (Santoro et al. 2006). Clearly, a lower amount of aquatic nirK sequences is available to test the existence of habitatspecific clusters. However, a study on the community composition of denitrifying bacteria along a gradient of salinity and nitrate demonstrated that nirK-communities were more strongly differentiated, even at very small spatial scales, than those carrying the nirS gene (Santoro et al. 2006). Also, our PCA of the clone libraries suggests that nirK-communities between different environments show a clearer differentiation than $n i r S$-communities, which appear to be more affected by the habitat in the same analysis.
This may indicate that differences in the properties of the enzymes could play an important role on determining the distribution patterns of denitrifying bacteria. Accordingly, NirK can be affected by factors that are determined in the environment (i.e., freshwater versus brackish water), while the functioning of NirS may be affected by habitat-specific factors such as co-factors availability, as has been suggested previously for the differentiation of nirS-communities in Lake Kinneret (Junier et al. 2008b). Overall, these results suggest an environment-specific distribution of nirS and nirK-containing denitrifiers and the potential existence of specific ecotypes within this microbial guild.

\section{References}

Aberle N, Wiltshire KH (2006) Seasonality and diversity patterns of microphytobenthos in a mesotrophic lake. Arch Hydrobiol 167:447-465

Altschul SF, Madden TL, Schäffer AA, Zhang J, Zhang ZWM, Lipman DJ (1997) Gapped BLAST and PSI-BLAST: a new generation of protein database search programs. Nucleic Acids Res 25:3389-3402

Avrahami S, Conrad R, Braker G (2002) Effect of soil ammonium concentration on $\mathrm{N}_{2} \mathrm{O}$ release and on the community structure of ammonia oxidizers and denitrifiers. Appl Environ Microbiol 68:5685-5692

Braker G, Zhou J, Wu L, Devol AH, Tiedje JM (2000) Nitrite reductase genes (nirK and nirS) as functional markers to investigate diversity of denitrifying bacteria in Pacific Northwest marine sediment community. Appl Environ Microbiol 66:2096-2104

Brettar I, Moore ERB, Höfle MG (2001) Phylogeny and abundance of novel denitrifying bacteria isolated from the water column of the central Baltic Sea. Microb Ecol 42:295-305

Castro-González M, Braker G, Farías L, Ulloa O (2005) Communities of nirS-type denitrifiers in the water column of the oxygen minimum zone in the eastern South Pacific. Environ Microbiol 7:1298-1306

Coyne MS, Arunakumari A, Averill BA, Tiedje JM (1989) Immunological identification and distribution of dissimilatory heme $c d l$ and non-heme copper nitrite reductases in denitrifying bacteria. Appl Environ Microbiol 55:2924-2931

Eckert W, Imberger J, Saggio A (2002) Biogeochemical response to physical forcing in the water column of a warm monomictic lake. Biogeochemistry 61:291-307

Falk S, Hannig M, Gliesche C, Wardenga R, Koster M, Jürgens $\mathrm{K}$, Braker G (2007) nirS-containing denitrifiers communities in the water column and sediment of the Baltic Sea. Biogeosciences 4:255-268

Hallin S, Lindgren PE (1999) PCR detection of genes encoding nitrite reductase in denitrifying bacteria. Appl Environ Microbiol 65 
Hannig M, Braker G, Dppner J, Jürgens K (2006) Linking denitrifier community structure and prevalent biogeochemical parameters in the pelagial of the central Baltic Sea Proper (Baltic Sea). FEMS Microbiol Ecol 57:260-271

Jayakumar DA, Francis CA, Naqvi SWA, Ward BB (2004) Diversity of nitrite reductase genes (nirS) in the denitrifying water column of the coastal Arabian Sea. Aquat Microb Ecol 34:69-78

Junier P, Junier T, Witzel KP (2008a) TRiFLe, a program for in silico terminal restriction fragment length polymorphism analysis with user-defined sequence sets. Appl Environ Microbiol 74:6452-6456

Junier P, Kim O-S, Witzel K-P, Imhoff JF, Hadas O (2008b) Habitat-partitioning of denitrifying bacterial communities carrying nirS/nirK genes in the stratified water column of Lake Kinneret, Israel. Aquatic Microb Ecol 51:129-140

Kim OS, Junier P, Imhoff JF, Witzel KP (2008) Comparative analysis of ammonia monooxygenase (amoA) genes in the water column and sediment-water interface of two lakes and the Baltic Sea. FEMS Microbiol Ecol 66:367-378

Knowles R (1982) Denitrification. Microbio Rev 46:43-70

Liu X, Tiquia SM, Holguin G, Wu L, Nold SC, Devol AH, Luo K, Palumbo AV, Tiedje JM, Zhou J (2003) Molecular diversity of denitrifying genes in continental margin sediments within the oxygen-deficient zone off the Pacific coast of Mexico. Appl Environ Microbiol 69:3549-3560

Michotey V, Mejean V, Bonin P (2000) Comparison of methods for quantification of cytochrome cd1-denitrifying bacteria in environmental marine samples. Appl Environ Microbiol 66:1564-1571

Nogales B, Timmis KN, Nedwell DB, Osborn AM (2002) Detection and diversity of expressed denitrification genes in estuarine sediments after reverse transcription-PCR amplification from mRNA. Appl Environ Microbiol 68:5017-5025

Oakley BB, Francis CA, Roberts KJ, Fuchsman CA, Srinivasan S, Staley JT (2007) Analysis of nitrite reductase (nirK and nirS) genes and cultivation reveal depauperate community of denitrifying bacteria in the Black Sea suboxic zone. Environ Microbiol 9:118-130

Overbeck J, Chróst RJ (1994) Microbial ecology of Lake Plußsee. Ecol Studies 105:1-44

Philippot L (2002) Denitrifying genes in bacterial and archaeal genomes. Biochim Biophys Acta 1577:355-376

Priemé A, Braker G, Tiedje JM (2002) Diversity of nitrite reductase (nirK and nirS) gene fragments in forested upland and wetland soils. Appl Environ Microbiol 68:1893-1900

Rai H, Arts MT, Wainman BC, Dockal N, Krambeck HJ (1997) Lipid production in natural phytoplankton communities in a small freshwater Baltic lake, Lake Schöhsee, Germany. Freshw Biol 38:581-590

Rösch C, Mergel A, Bothe H (2002) Biodiversity of denitrifying and dinitrogen-fixing bacteria in an acid forest soil. Appl Environ Microbiol 68:3818-3829
Santoro AE, Boehm AB, Francis CA (2006) Denitrifier community composition along a nitrate and salinity gradient in a coastal aquifer. Appl Environ Microbiol 72:2102-2109

Satoh T, Hoshino Y, Kitamura H (1976) Rhodopseudomonas sphaeroides forma sp. denitrificans, a denitrifying strain as a subspecies of Rhodopseudomonas sphaeroides. Arch Microbiol 108:265-269

Schäfer H, McDonald IR, Nightingale PD, Murrell JC (2005) Evidence for the presence of a CmuA methyltransferase pathway in novel marine methyl halide-oxidizing bacteria. Environ Microbiol 7:839-852

Schloss PD, Handelsman J (2005) Introducing DOTUR, a computer program for defining operational taxonomic units and estimating species richness. Appl Environ Microbiol 71:1501-1506

Sharma S, Aneja MK, Mayer J, Munch JC, Schloter M (2005) Diversity of transcripts of nitrite reductase genes (nirK and $n i r S$ ) in rhizospheres of grain legumes. Appl Environ Microbiol 71:2001-2007

Taroncher-Oldenburg G, Griner EM, Francis CA, Ward BB (2003) Oligonucleotide microarray for the study of functional gene diversity in the nitrogen cycle in the environment. Appl Environ Microbiol 69:1159-1171

Throbäck IN, Enwall K, Jarvis ^, Hallin S (2004) Reassessing PCR primers targeting nirS, nirK and nosZ genes for community surveys of denitrifying bacteria with DGGE. FEMS Microbiol Ecol 49:401-417

Throbäck IN, Johansson M, Rosenquist M, Pell M, Hansson M, Hallin S (2007) Silver $\left(\mathrm{Ag}^{+}\right)$reduces denitrification and induces enrichment of novel nirK genotypes in soil. FEMS Microbiol Lett 270:189-194

Tuomainen JM, Hietanen S, Kuparinen J, Martikainen PJ, Servomaa K (2003) Baltic Sea cyanobacterial bloom contains denitrification and nitrification genes, but has negligible denitrification activity. FEMS Microbiol Ecol 45:83-96

Wolsing M, Priemé A (2004) Observation of high seasonal variation in community sturucture of denitrifying bacteria in arable soil receiving artificial fertilizer and cattle manure by determining T-RFLP of nir gene fragments. FEMS Microbiol Ecol 48:261-271

Yan T, Fields MW, Wu L, Zu Y, Tiedje JM, Zhou J (2003) Molecular diversity and characterization of nitrite reductase gene fragments (nirK and nirS) from nitrate- and uranium-contaminated groundwater. Environ Microbiol $5: 13-24$

Yoshie S, Noda N, Tsuneda S, Hirata A, Inamori Y (2004) Salinity decreases nitrite reductase gene diversity in denitrifying bacteria of wastewater treatment systems. Appl Environ Microbiol 70:3152-3157

Zumft WG (1997) Cell biology and molecular basis of denitrification. Microbiol Mol Biol Rev 61:533-616 